\title{
Linguocultural Framework of Russian Dacha Gastronomic Culture in Today's Mass Media
}

\author{
V.V. Zhura, Yu.V. Rudova * \\ Volgograd State Medical University, Department of Foreign Languages with a Course of Latin, Volgograd, \\ Russia
}

\begin{abstract}
For a number of decades, both Russian and international researchers have demonstrated their unremitting interest in a such specific Russian phenomenon as dacha. Yet, the linguocultural aspects of its constituent gastronomic culture in Russia have not been studied. The study comprised several stages, at which the methods of hermeneutics, content analysis, narrative interviewing with subsequent linguistic analysis were employed. The significance of Russian dacha in shaping eating practices is reflected in communal and individual consciousness which is implicated in the broad coverage of this topic by the mass media. The linguocultural framework of the dacha gastronomic culture of Russia has been demonstrated by the thematic content of mass media texts and by cumulative and individual concepts evolved by the participants of dacha movement. We have found that such linguocultural concepts as special importance of a dacha diet and dacha foods, their uniqueness, health utility, simplicity and naturalness, hedonic value, festivity, and communal nature are most explicitly represented in the texts. Furthermore, recreational and ingenious potential of dacha activities embedded in a remarkable emotional atmosphere is semantically embodied. We have shown that the analyzed texts are impregnated with emotional and evaluative connotations verbalized by means of specific lexical and syntactical stylistic devices.
\end{abstract}

\section{Introduction}

Social values and rules reflected in the linguistic world view are largely shaped by cultural and historical practices which have evolved in a community. The unique experience accumulated by a community or its particular constituent social group, typical traditions and lifestyle patterns form a conceptual framework for perceiving and appreciating reality. They also predetermine socially acceptable activities and practices and develop language consciousness inherent in a particular culture. An important aspect of conceptualizing reality is acquisition and comprehension of axiological and emotional concepts associated with it. The analysis of such specific Russian phenomenon as dacha movement tends to be illustrative in a study of linguocultural specificity.

This phenomenon is salient, multifaceted and broadscale, which has given rise to its new understanding. Today, it is defined as a specific subculture within the Russian society termed as dacha culture (Dzhandzhugazova, 2010).

Numerous studies have repeatedly focused on dacha households. Various aspects of this phenomenon have been analyzed in theoretical papers: historical (Varaksin, Nefodina, 2011; Lovell, 2003), social, economic and political (Caldwell, 2011), sociocultural (MalinovaTziapheta, 2013), demographic (Rusanov, 2015), legal (Butovetsky, 2014), and geoecosysystemic issues (Nekhaeva, 2004). However, so far no studies have focused on the linguocultural aspects of dacha practices, which have given rise to a special dacha culture of eating.

The purpose of this study was to identify and demonstrate the linguocultural conceptual framework of the dacha culture of eating in Russia in various media texts and individual narratives of the participants of dacha movement.

\section{Materials and methods}

To conduct our research, we relied upon three types of narrative data: 1) current Russian and international articles and monographs, providing information on the major vectors of theoretical investigation of dacha practices; 2) media texts, covering mass media publications, websites of various public organizations

*Corresponding author: juliarud@inbox.ru 
and associations of dacha residents and owners, and social network materials; 3 ) individual narratives of the partcicpants of dacha movement collected and analyzed by the authors.

The methods of hermeneutic research (Boell, CecezKecmanovic, 2014), content analysis of mass media and website materials, narrative interviewing and discourse analysis involving the techniques of interpretative and stylistic analysis of the texts were used to obtain the relevant information and analyze the findings.

The methods of systematic review and hermeneutic analysis of literature made it possible to select the relevant orgininal studies and subsequently conduct a critical evaluation of the published data with regard to the problem in question.

The content analysis of mass media texts involved working out a conceptual-categorical apparatus reflecting the main topics represented in them (e.g., dacha diet, dacha recipes, etc.).

Narrative interviewing was performed by a semistructured interview including two stages : 1) basic story initiated by a narrative trigger (questions such as Why do you need a dacha ?) ; 2) stage of narrative-stimulating questions when leading questions about the facts and events related illogically in a story were asked.

Linguistic methods were used to identify the concepts incorporated in the discourse and verbal means employed.

\section{Results}

At present, dacha is defined as a specific sociocultural phenomenon and an organizational form of vital activities in Russia (Rusanov, 2015). Russia's dacha movement dates back over centuries. The historians claim that it emerged in the 19th century and involved building summer settlements in the vicinity of the captitals (Moscow and St Petersburg).

At that time, a dacha was not a private subsidiary farm but was rather a resting place for well-to-do city dwellers and middle class people, who were tired of the hustle and bustle of the metrolpolitan cities (Elyugin, 2014). Alongside with outdoor recreation activities, dacha residents were gradually getting down to gardening. The roots of the city dwellers, who originally hailed from rural areas as well as their psychology imposed by the agrarian type of the national economy, accounted for a tendency towards agricultural activities.

Their food ration was also distinctive. It included foods produced or gathered by the residents of the nearby villages - dairy products, meat, vegetables and fruit, fish, mushrooms and berries.

A distinctive dacha ration was gradually evolving. It tended to combine plain and fresh agricultural products cultivated by dacha dwellers and special leisure ways of cooking.

The detailed analysis of the dacha movement development at different stages of the Russian history is beyond the scope of this study. However, it is essential to outline the main landmarks, which have given an impulse to the transformation of dacha households into their current state represented in media texts and individual narratives.

The Food Programme of the USSR enacted in 1982 was intended to make up for the food deficit. It aimed to extend the potential involvement of private subsidiary farms, vegetable and fruit growing housholds to solve the problem (Bogolyubov, 1983).

The crisis time, which Russia went through in the 1990s, was another stimulus for dacha movement expansion.

Although recently we have witnessed a shift away from agricultural dacha activities, the dacha culture of eating still retains and keeps on developing its specificity.

Moreover, as it is closely associated with the notion of gastronomic culture, the latter has to be considered.

The analysis of this notion implies transcending the understanding of bilogical nature and importance of eating and rather regarding it as a phenomenon of culture operating within a particular sociocultural context.

This approach aims to study people's life events (e.g., every day meals, wedding feasts, birthday parties) and specific behavioural patterns (including verbal behaviour) associated with them.

In this case, food acquires both biological and symbolic importance impregnated with evaluative and emitional connotations.

Therefore, gastronomic culture is a systemic phenomenon including three basic components - culture of cooking food (rules, instructions and patterns of cooking food, a set of accepted products and their combinations), culture of food consumption (table manners, eating practices and traditions), and reflection over the processes of cooking and eating (various media texts about dacha eating practices) (Kapkan, Likhacheva, 2008).

The dacha context adapts all the three components of gastronomic culture, which acquires concrete and specific content imposed by the specificity of this sociocultural pratice.

As aforesaid, our study aims to explore the reflection over the dacha culture of eating, whose linguocultural features may be represented textually.

Such reflection may be both objective and subjective. In the former case, knowledge generation is implied; its results are presented in research papers. Subjective reflection embedded in mass media materials and individual narrarives of dacha holders plays an important role in assessing the role of dacha eating practices in evolving gastronomic culture and healthy living. Therefore, it claimed our close attention.

On the one hand, mass media publications represent the gastronomic world view which has evolved in the community; on the other hand, they convey the messages about healthy/unhealthy eating, thus shaping public opinion on these issues.

One of the central topics discussed in today's mass media internet discourse is a dacha diet. It embraces such components of the gastronomic culture as products cultivated at dachas, their cooking and consumption. Evaluative and emotional dimensions of this phenomenon are also explicated. 
The importance of the dacha diet in the life of Russian people is implicated, primarily, in a long list of available online media outlets (in our study we used the materials of 30 web papers) publishing articles on this topic - «Cooking at a Dacha», «Favourite Dacha», «Dacha Quisine: for Eating and for Preserving», «Fruit and Vegetable Garden as a Family Provider and Healer», «Dacha Specialist», «Dacha all the Year Round», «Dacha Secrets», «Dacha and Life», etc.

The analysis of 54 headings of web columns and their content made it possible to identify a few broad thematic categories, representing the dacha diet - healthy dacha products (Health from the garden bed, Keep healthy, Health and Nutrition), dacha dishes and dacha menues (Dacha quisine, For a cookery-book, Dacha recipes, Dacha preserves, Sharing experience) as a whole or its subcategories reflecting various pragmatic aspects of dacha eating - originality (dacha menu : what novel dish to cook?), utility (a menu for dacha : cooking fresh vegetables), hedonitistic vaue (quick and tasty dacha recipes, grilled dishes), festivity (dacha New Year, a menu for a dacha party), adaptability to consumers' needs (dacha menu for a child, dacha menu for the whole family).

The analysis of the content of web articles has revealed the following subcategories representing various aspects of dacha eating practices: 1) qualitative parameters (ecological properties of foods, tastiness, utility, freshness of dacha products, their healing power) ; 2) technological parameters (ways of cooking dacha products) ; 3) chronotopos parameters (time and place of having dacha meals).

The aforesaid may be illustrated by a few excerpts from the articles published in the earlier mentioned web outlets. The author of the first excerpt, the editor of the Your 6 Hundred Square Meters newspaper, addresses his readership in a letter, 'For myself and my family - only the tastiest and the most wholesome. To say nothing of ecological cleanliness. Once I met a Dutch farmer, he boasted of his ecologically pure potatoes which had been sprayed with toxic chemicals just seven times! But I don't chemicalize mine at all. The Dutchman must have left me behind as to the output of products, but he is unlikely to do so with regard to ecology...' (Tumanov, 2015). The factual content of the story includes semantic propositions stating ecological purity of the products, a refusal to use toxic chemicals, and, as a result, lower output harvested. The second type of message conveyed in the text is embedded in its emotional and evaluative connotations explicating the author's feelings (pride, satisfaction with the obtained results). It has been verbalized with a number of syntactical means employed in the excerpt (inversion, exclamatory sentences, ellipsis), stylistic devices (irony, antithesis) and has a cathartical effect on the mental and phsyical health of the narrator.

The suggested recipes including ingredient desciptions and ways of cooking differ substantially from the tradional cookery-books, as they abound in the authors' subjective evaluations and create a special emotional atmosphere for food consumption.
Just as in the previous excerpt, an important linguistic feature of the text presented below is its narrative nature. It is embodied through a variety of lexical and syntactical means typical of everyday spoken language (ellipsis, exclamatory sentences, inversion, colloquialisms such as tater, rots). 'Now I am going to share my favourite and, above all, a simple recipe from my dacha quisine. Called 'Ragout from anything you have!' I pick whatever has ripened in the vegetable garden : tater, tomatoes, vegetable marrow, onions, rots (for carrots), turnip, sweet pepper, peas, spices... I stew on a low heat. Turns out to be tasty and rich!'.

Another essential linquocultural attribute of the web publications on the dacha diet consists in their emphasis on the role of dacha products and ways of their cooking and consumption in living a healthy lifestyle and on its potential effects on the human body (to revitalize and decrease excessive weight).

'A vegetable marrow diet has been one of the most popular summer diets in the past years. As soon as the season of young marrows comes, a lot of women start keeping to this diet, which is also known as a dacha diet. The thing is that a vegetable marrow is the most delicious and low-calorie product, accessible to all and very wholesome by that. Water makes up $95 \%$ of marrows as well as cucumbers and they are low-calorie. $<\ldots>$ This diet suggests using vegetable marrows as a basis which can be varied with meat, fish, and poultry. The main thing is proper cooking. You can complement the menu with seasonal berries and fruit as well as cereals...'.

'Firstly, have six meals a day, and they must be healthy. Here is a one day sample menu: 1. Breakfastskim cheese with berries; you can use any berries. 2. Branch - a couple of apples or some other fruit. 3. Lunch - fried vegetable marrows, or grated carrots, or pepper cut into pieces. Here alternatives are endless. Dessert - a couple of berries or fruit. 4. Nuncheonkefir or yogurt. 5. Dinner - meat or shashlik. In general terms, there may be many variants of dacha diet, but everyone will like this one' (Polezhaev, 2014).

On the one hand, the texts of the pre-cited publications imitate the narrative style and syntax, which show deviations from the strict rules of the standard language. On the other hand, they tend to be similar to dialogical speech owing to the use of imperative sentences (have six meals a day), modal verbs (You can complement the menu with seasonal berries and fruit; they must be healthy).

The choice of these linguistic resources is deliberate and aims to reduce a communicative distance between the text sender and the text recipeint which is essential for creating a special emotional atmosphere associated with dacha life and producing the required impact.

Another aspect of dacha eating covered by mass media describes its technological parameters, namely, ways of cooking foods at a dacha. Cooking dacha dishes is distinctive in terms of freshness of ingredients, simplicity, naturality of the aids used, and ways of food procession. The symbolic meaning of dacha eating practices consists in going back to our roots, profound human self-purification achieved through the emotional 
merging with nature. 'How pleasant it is to eat the first small sweet rot, to fry the most delicate vegetable marrow, to boil young tater', 'Dacha food is substantially different from what we cook and eat in town. We have access to open fire, to fresh, 'our own' vegetables and fruit...', 'What can you cook at a dacha? Simple dishes which do not require special appliances and a lot of kitchenware $\langle\ldots>$ you don't want to waste much time on culinary delights outdoors... '.

These texts show a high density of emotional connotations which are verbalized by appealing to emotionally-laden concepts (open fire, the first small sweet rot), using diminuitive suffixes, superlative adjectives and the stylistic device of antithesis (Simple dishes - culinary delights).

The analysis of the chronotopos parameters of dacha eating demonstrates its communal nature. The most significant individual concepts represented in mass media texts encompass the place of having a dacha meal (outdoors - on the terrace or sun-lounge, under the tilt), non-adherence to table etiquette, relaxed and informal atmosphere. 'And a trivial, and most common lunch is turning into a long and and tasty get-together which is smoothly converting into dinner...' (Ryzhova, 2012). To convey these concepts, the authors have employed the stylistic devices - epithets (tasty get-together), semantic reduplication.

The explicated vectors of conceptualizing the dacha gastronomic culture demonstrate that, evolving within a leisure practice, it acquires both objective content (particular products and their nutritional profile, ways of cooking and consuming food) and evaluative and emotional connotations, which highlight its great socioand linguocultural significance.

To reveal the conceptual framework of the phenomenon under study in the Russian linguoculture we also drew on individual narratives of the national dacha holders. This part of our research has revealed a number of individual concepts reinterantly represented in the narratives, which made it possible to typify them and consider as regular linguocultural entities in the life sphere in question.

The first concept uncovers the motivation for spending time at a dacha, which is undergoing changes at present. $100 \%$ of the narrative authors stated that the main reasons for going to dachas were recreation and social life. 'As for me, I need dacha for rest but also to work a little, broadly speaking, to keep myself engaged in something...', 'Solely to escape the city. Not to stay in town for the weekend', 'Dacha? Dacha is needed to have a civilized rest'.

Another important aspect of the dacha culture of eating is related to growing own vegetables and fruit. The narrarive semantics analysis has demonstrated that a dacha household is not perceived by its owners as a way of supplying themselves with food, but rather as a form of experimenting and fulfilling their creative potential. 'What did we discover for ourselves? We discovered a lot. Never have we grown summer squash. Discovered them just a few years ago. And now it's a miracle! It's another potatoes which are surely not so rich in calories. We started cultivating corn. It went ahead. And we all like it. It's fuss-free. But all like it, adults and children. What else? Well,.. pumpkin. In the past two years it has shown a dash. We just planted it. Just for fun. On meagre soil. And it went ahead. It's also nice. Stewed and baked and mush and everything. This is what we have discovered in the recent years', 'We plant out of curiosity. This year I want to plant eight to twelve kinds of hot pepper over there. To see what it looks like. How hot it is! And I find out about them mainly from the Internet. I am just curious'.

The emotive potential of these narratives is verbalized through the use of a great number of vocabulary, whose meaning includes positive evaluative connotations (fuss-free, miracle, nice), as well as anthropomorphical metaphorization of the grown plants (It went ahead, shown a dash, To see what it looks like).

Another linguocultural aspect of dacha eating conceptualized in individual narratives covers the ways of processing harvested products. The major ways of food procession ensuring access to dacha products throughout the year are conservation, drying, freezing vegetables and fruit. The authors of the narratives point out that the above-mentioned ways of storing food make it possible to fully preserve their nutritive properties, ensure an adequate intake of the required vitamins all the year round.

Verbally, such texts employ a great number of reflexive and possessive pronouns, the stylistic device of antithesis highlighting intense emotion-laden connotations of the narrative content. 'First thing, conservation. Not to buy in a shop, but to take out of the cellar. Well, we eat at the dacha. We share with people. Everything is consumed by ourselves', 'Processing, drying fruit, making juice. And eating them fresh', 'How are they consumed? In the first place, for myself! We eat. Store for the winter. You know, I don't buy any tomato pastes. Only my own borsch seasonings. If anything is excessive, I give it away. Besides, freezing. No other ways', 'Certainly, we eat them on our own. It would be strange if you grew them yourself but wouldn't have a bite.'

The authors point up the differences in ways of cooking and consuming food at home and in the dacha settings. These differences embrace the following aspects: a set of the products used, the number and time distribution of meals, particular ways of cooking dishes, the environment for eating, the involvement of special food-related rituals, emotional atmosphere.

The cooked dishes show a distinctive dacha flavourgreen omlette, vegetable ragout, sorrel soup, compot, dacha fruit mush. They synthesize traditional recipes of the Russian quisine and experiments using what is available hic et nunc. Therefore, you cannot expect universal and long-standing culinary discoveries. Every dacha holder has their own collection of recipes. Emphasis is placed on cooking various dishes from vegetables and fruit, careful consideration of their wholesome properties, and simplicity of cooking. 'We fry beetroot there, here at home we very seldom do it. You can grate it or simply cut into cubes. You also fry tater and then mix it all together. Carrots also in there. It's amazing there!»' 
Meals are distinctive for their democratic character; their number and timing can vary depending on different factors (being engaged in some activities, visiting friends, etc.).

As a rule, table setting highlights simplicity and natural beauty of the harvested products. Whole or cut vegetables and fruit are often served with no dressings. These linguocultural specifics of eating are reflected both in the individual narratives and mass media texts. 'Many people are sure to agree with the idea that dacha eating (both cooking and consumption) substantially differs from what we cook and eat in town. You have an access to open fire, to popping fresh, your own vegetables and fruit and even mushrooms. When you can lay "odd" tableware to feel informal and simple dacha living'.

To convey the linguocultural concepts of simplicity and naturalness of a dacha meal the authors turn to evaluative and emotive vocabulary (popping fresh, your own, "odd" tableware, informal and simple dacha living), the stylistic device of antithesis.

Another reiterant conceptual entity, which is represented in both mass media texts and individual narratives, discloses the communal nature of dacha cooking. There are specific dishes, which are cooked by different participants (i.e., shashlik is traditionally made by men, whereas compot is stewed by the representatives of older generations - grandmothers). Cooking a dish may become a specific ritual which acquires such attributes as relative stereotypy, interactivity, festivity, symbolism (open fire as a symbol of merging with nature and going back to ancient roots), emotional and evaluative connotations.

'There are numerous views of who must make and roast shashlik. In our family, I marinate meat, the man's business is to choose and buy meat, as well as to stock wood, make a fire and roast meat. My husband roasts meat on the smouldering fire for 10 minutes and the meat melts in your mouth and well-done! My girl friends and I have tried to do this on our own, we roasted for 20 minutes and still some parts were burnt, some were dry, others were underdone'.

The rituality of dacha cooking has proved to be a significant linguocultural concept conveyed in the analyzed texts. The most popular rituals include those of making meat and fish shashlik, pilaw and vegetable dishes grilled over the fire. The traditional way of cooking shashlik preferred by gourmets requires the wood collected and prepared with their own hands from dried fruit trees instead of coal bought in a shop.

Making a fire, maintaining the suitable heat and flavor spreading around from the dish being cooked create a sacral atmosphere and promote merging with human natural environment. The communal way of making dishes embeds dacha eating in the aura of shared understanding and mutual help.

The particular settings of dacha meals have also been explicated in the texts. They are usually held outdoors (on the veranda or in the gazebo) in the family circle or with other people present as guests. Informal chatting, which is hardly ever possible in the town settings due to the time pressure, is considered to be quite common here.

These ideas are made explicit in the narrative below.

'A dacha meal is usually much longer and more relaxed and, finally, more pleasant than that in town. For a example, a breakfast on the terrace! When you can - in no hurry - discuss your plans for a long-long summer day... When you can have a coffee to the 'live sound' of birds' morning arias'.

The revealed linguocultural concepts are verbalized by means of a comparison (A dacha meal is .. more pleasant than that in town), lexical and syntactical reduplication, words with evaluative connotations, a metaphor (live sound' of birds' morning arias).

All the analyzed excerpts demonstrate that dacha eating practices are positively evaluated events which result from the appreciation of the valuable and tangible artefacts of people's own labour obtained in the form of harvested products.

\section{Conclusion}

The linguocultural framework of the Russian dacha gastronomic culture has been constructed by analyzing the reflection over this phenomenon represented in mass media texts and individual narratives of dacha owners.

Numerous web outlets foreground such liguocultural concepts as the special role of the dacha diet and dacha food, its uniqueness, utility, simplicity and naturalness, hedonic value, festivity, and communal nature, which make the dacha culture of eating in Russia distinctive.

The explicated cumulative and individual conceptual entities evolved by the participants of dacha movement have made it possible to upscale the linguocultural significance of the dacha gastronomic culture. We have demonstrated that its interpretation comprises special recreational activities to fulfill a person's potential by growing, cooking, preserving and consuming food products and create a positive emotional atmosphere.

\section{References}

1. E.A. Dzhandzhugazova, Modern problems of of service and tourism, (2010)

2. G.S. Varaksin, T.A. Nefodina, The Bulletin of the Krasnoyarsk state agrarian university (2011)

3. S. Lovell, Summerfolk: A History of the Dacha. (Ithaca and London: Cornel University Press, 2003)

4. M.L. Caldwell, Dacha idylls: Living organically in Russia's countryside. (Berkeley, L.A.: University of California Press, 2011)

5. O. Malinova-Tziapheta, From town to dacha. Sociocultural factors of building summer settlements in the vicinity of St. Petersburg (1860-1914). (St.Petersburg: European university publishers, 2013)

6. A.V. Rusanov, The specific features of dacha suburbanization in Russian as exemplified by the 
Moscow region. (Economic and social changes: facts, tendencies, forecasts, 2015)

7. A.I. Butovetsky, Garden, vegetable garden and dacha non-profit partnerships as estate partnerships. (Law. The Journal of the Higher School of Economics, 2014)

8. N.E. Nekhaeva, Monitoring of land use for gardens and vegetable gardens as exemplified by Saransk. (2004).URL:

http://www.niioncologii.ru/sites/default/files/files/20 140706104624.pdf.

9. S.K. Boell, D. Cecez-Kecmanovic, A hermeneutic approach for conducting literature reviews and literature searches. (Commun. Assoc. Inform. Syst. 2014)

10. O. Elyugin, Dacha is our symbol of life. (Science and life, 2014)

11. K.M. Bogolyubov, The Food Programme of the USSR: the content and ways of turning it into reality. (M. : Politizdat, 1983)

12. M.V. Kapkan, L.S. Likhacheva, The Ural State University Review. Arts 55(15) (2008)

13. A. Tumanov, A dacha diet is a holiday, The Your 6 Hundred Square Meters newspaper (2015), URL: http://sotki.ru/obmen_opitom/article/dachnayadieta--eto-prazdnik-3601 (date of access: 22.07.2015)

14. S. Polezhaev, A dacha diet or dacha as a bodybuilder, 2008-2017 - Tea Road (2014), URL: http://www.tearoad.ru/dachnaya-dieta-ili-dacha-kaktrenazher/ (date of access: 21.02.2014)

15. I. Ryzhova, On food. Dacha eating practices, The Commentaries of I. Ryzhova about food (2012), URL: http://www.abcslim.ru/articles/1051/pro-eduedim-na-dache/ 